\section{A CASE OF SCLEREMA NEONATORUM.}

BY

\section{W. GIFFORD NASH, F.R.C.S.,} BEDFORD.

Sclerema neonatorum appears to be sufficiently uncommon in Great Britain to render the following case worthy of record.

A female infant, aged 2 months, was first seen by me on January 11th, 1924. The father, aged 44 , and the mother, aged 33, had for some years resided on the Gold Coast. This was their first child. The mother about a month after she became pregnant came to England suffering from bacilluria, and this was still present in February, 1924. The father denied any history of syphilis. The child was born in South Devon on November 9th, 1923, and at birth weighed $8 \mathrm{lb} .3 \mathrm{oz}$. It is possible she was a ten months baby. At birth she was blue owing to compression of the cord. A few days after birth oedema was noticed, and this gradually increased in hardness and extent. She was artificially fed from birth. On November 28th it was noted that the arms above the elbows were very hard and the buttocks very hard and lumpy. This hardness continued to increase until the whole of the back and all the extremities were involved.

On January 10th, 1924, when she came to Bedford, the hardness at the back of the neck was getting less. It was noticed that the child was more fretful on cold days.

On January 11th I saw the infant and found her fairly well nourished. 'The skin was yellowish and the mucous membranes blue. There was a widespread hardness of the subcutaneous tissue, which felt like that of a dead foetus in winter. The parts chiefly involved were the shoulders, back, buttocks, and all the extremities. In the latter the tissues involved felt like hard ropes. The face was not affected. The skin did not pit on pressure. There was no albuminuria or heart disease. The temperature was normal. The diagnosis was sclerema neonatorum. The treatment consisted of keeping the child warm with woollen clothes and hot bottles. 'Two hot baths were given daily and were a source of pleasure to the infant. One grain of grey powder was given three times a day and has been continued up to the present time, April 28th. Under this treatment the child progressively improved, the colour became healthy, and the weight steadily increased. The hardness gradually dissolved, the masses and cords breaking up into islets, and now has all but gone.

The best description of sclerema neonatorum I have found is in Diseases of Children, by Garrod, Batten, and Thursfield. They describe a group of four diseasesnamely, sclero-oedema, sclerema, pseudo-sclerema, and sclerodermia. The second and third are the only two which concern us. The difference appears to be that sclerema attacks wasted children and is nearly always fatal, and pseudo-sclerema attacks well nourished children and is usually recovered from. This distinction appears to me to be artificial.

I would suggest that the disease is the same, the difference being in the soil-that is, in the state of nutrition of the infants.

\section{ftemaranda:}

\section{MEDICAL, SURGICAL, OBSTETRICAL.}

\section{CEREBRAL HAEMORRHAGE AND CONGENITAL OBLITERATION OF THE GALL BIADDER AND DUCTS IN AN INFANT.}

This case was the subject of an inquest. I was called for the first time soon after death, and had never seen the child during life.

The infant, 2 months old and of corresponding weight, was jaundiced to a lemon colour. The history, afterwards elicited, showed that jaundice first appeared at the age of 3 weeks and had persisted. No black meconium had been passed and the motions were always white. The baby was breast-fed, gained weight well, and did not seem iil till a few days before death, when a slight cough was noticed. The night before it died it was restless, but early the next morning went to sleep and later on was found to be dead.

Post-mortcm Excmination.- The baby was well nourished, with good fat deposit. 'The gall bladder was absent, but represented by a layer of fibrous tissue where it should have been. ${ }^{*}$ The common bile duct was found to be patent for some distance, but no entrance into the duodenum existed. The liver was hard on section, dark olive-green in colour, and the bile passages were largely obliterated and replaced by fibrous tissue. The spleen was not enlarged but very dark in colour. The thym was unusually large and th thyr dark in colour. The thymus was unusually large and the thyroid was well developed. Both lungs presented early signs of bronchopneumonia. The brain showed a large haemorrhage in the left hemisphere, composed of a clot the size of a pigeon's egg and semi-clotted blood of about equal amount. The haemorrhage was inside the cortex and had evidently come from the internal capsule.

This child could, of course, never have lived long. It was no doubt the efficient breast-feeding that enabled it to survive for two months. It fell an easy prey to infection of the air passages, and the haemorrhage was probably due to a weakening of the vessel wall from the persistent jaundice.

The combination of a large cerebral haemorrhage with congenital obliteration of the gall bladder and ducts appeared to make the case worth recording.

Howari) Gladstone, M.D. Honorary Medical Officer, Sydenham Infant Welfare Centre.

TARTAR EMETIC IN TUBERCULOSIS.

The beneficial effect of tartarated antimony in acute and chronic bronchitis influenced practitioners to use it in the treatment of tuberculous disease of the lungs; but the depressive effect, associated with the tendency to vomit, that is produced when the drug is given by the mouth rendered it unpopular. When given intravenously tartar emetic produces vomiting only when the large doses necessary to eradicate the larger parasites of the blood strean are employed; doses of only half a grain have a stimulating effect on most patients. Tartar emetic, therefore, deserves a further trial in the treatment of tuberculous disease of the lungs. One or more such intravenous injections might reasonably be supposed to help in cleaning up a "dirty sputum", and thus render the system more able to deal with the presence of the tubercle bacillus, even if no destructive effect on the tubercle bacillus would become evident. In the same way, by destroying associated microorganisms, such drugs as tartar emetic and manganese help the gonococcus to die out more rapidly than it would otherwise.

The immediate relief of paralysis and other signs of leprosy following injections of antimony in certain cases indicates that the drug has some more decided effect on the disease than the mere cleaning up of associaterl conditions; but, even were it to do no more than to help in cleaning up ulcerated patches and other skin conditions that are early or late features of a very intractable disease, it would render the patient better able to deal with the leprosy bacillus and render this bacillus the more likely to die out.

The rapid relief that is sometimes experienced in syphilitic and leprotic disease of the eye likewise suggests that intravenous injection of antimony might be of service in tuberculous disease of the eye; its proved value in many skin conditions suggests that it has not yet received the attention it deserves in cleaning up cancerous growths in various parts of tho body, even though antimony ointment has been extensively used for these conditions.

Durban, Natal. F. G. Cawston, M.D.Cantab.

\section{INTRACARDIAC INJECTION OF ADRENALINE.}

THE following case tends to support the opinion that adrenaline administered by injection into the heart is very greatly superior to the usual cardiac stimulants in cases where there is a sudden failure of the heart.

On January 9th, 1924, at about 12.45 p.m., a young, exceptionally well built Chinese male was carried into my office on the back of another man. He was breathing rapidly, his whole skin was cyanosed, and he was obviously in a very serious condition, though cyanosed, and he was obviously in a very serious condition, though
able to sit up and to talk. The apex beat of the heart was slightly able to sit up and to talk. The apex beat of the heart was slightly displaced outward; no murmurs were heard; the legs were slightly
oedematous. The temperature was subnormal; nothing else of oedematous. The temperature was subnormal; nothing else of
note was found. He was bled a few ounces and injections of ether, digitalin, and camphor given. There was no noticeable improvement. His condition got worse until there was no pulse felt at the wrist, and finally he appeared on the very point of dissolution, respiration being jerky, extremely shallow, occurring once 